\title{
Early and delayed atrioventricular conduction block after routine surgery for congenital heart disease
}

\author{
Angela Lin, BS, ${ }^{a}$ William T. Mahle, MD, ${ }^{b}$ Patricio A. Frias, MD, ${ }^{b}$ Peter S. Fischbach, MD, ${ }^{\mathrm{b}}$ \\ Brian E. Kogon, MD, ${ }^{\mathrm{c}}$ Kirk R. Kanter, MD, ${ }^{\mathrm{c}}$ and Paul M. Kirshbom, $\mathrm{MD}^{\mathrm{c}}$
}

Objectives: Patients undergoing surgical closure of ventricular septal defects are at risk for immediate or delayed
atrioventricular conduction block. Our goal was to better define the incidence of delayed atrioventricular conduc-
tion block.

Methods: A retrospective review was conducted of hospital records and pacemaker database for ventricular septal defect, atrioventricular canal, and tetralogy of Fallot repairs between 1999 and 2004. A total of 922 patients were identified (atrioventricular canal in 197, tetralogy of Fallot in 222, and ventricular septal defect in 503). Median follow-up was 4.1 years.

Results: There were 472 male and 450 female patients, median age 6 months ( $0-444$ months) and median weight $5.8 \mathrm{~kg}(1.3-116 \mathrm{~kg})$ at surgery. Postoperative atrioventricular conduction block developed in $21(2.3 \%)$ of the 922, being transient, with return of conduction 3 days (1-14 days) after surgery, in $13(1.4 \%)$ and permanent, with pacemakers implanted 10 days (6-20 days) after surgery, in $8(0.9 \%)$. Of the 905 patients at risk for delayed atrioventricular conduction block, $3(0.3 \%)$ had second- or third-degree block at 2, 8, and 16 months after surgery. Two of these 3 had transient postoperative block. For isolated ventricular septal defects, the incidence was 1 $(0.2 \%)$ of 496 . There were 8 late deaths at 31 months ( $7-45$ months) after surgery. Five had normal conduction at death, but for 3 patients the conduction status at death could not be determined. Including these 3 patients as possible cases of delayed atrioventricular block yields an incidence of $0.3 \%$ to $0.7 \%$.

Conclusions: The incidence of early atrioventricular conduction block requiring a pacemaker was $0.9 \%$ and that of delayed atrioventricular conduction block was $0.3 \%$ to $0.7 \%$. Transient atrioventricular conduction block may be a marker for increased risk of delayed block. These data may be useful for evaluation of new techniques.

(J Thorac Cardiovasc Surg 2010;140:158-60)

A significant percentage of surgical procedures for congenital cardiac disease require closure of a ventricular septal defect (VSD). ${ }^{1}$ A widely recognized risk of VSD closure is injury to the conduction system, which can lead to early or delayed complete heart block requiring placement of a permanent pacemaker. ${ }^{2-5}$

The incidence of early postoperative heart block has been reported to be between $0.7 \%$ and $3 \%$ depending on the era of surgery and the cardiac lesion. ${ }^{2,6}$ The occurrence of late-onset complete heart block was first described more than 3 decades ago in the early surgical era. ${ }^{7}$ Although more recent studies have described the characteristics of patients who have required pacemaker implantation owing to delayed heart

From Case Western School of Medicine, ${ }^{a}$ Cleveland, Ohio; Emory University Division of Cardiology, Department of Pediatrics, ${ }^{b}$ and Emory University Division of Cardiothoracic Surgery, Department of Surgery, ${ }^{c}$ Atlanta, Ga.

Disclosures: None.

Read at the Fifty-eighth Annual Scientific Sessions of the American College of Cardiology, Orlando, Florida, March 2009.

Received for publication June 15, 2009; revisions received Nov 12, 2009; accepted for publication Dec 20, 2009; available ahead of print April 12, 2010.

Address for reprints: Paul M. Kirshbom, MD, 1365 Clifton Rd, A2100, Atlanta, GA 30322 (E-mail: paul.kirshbom@emoryhealthcare.org).

0022-5223/\$36.00

Copyright (c) 2010 by The American Association for Thoracic Surgery doi:10.1016/j.jtcvs.2009.12.050 block, ${ }^{4}$ the incidence of this complication has not been reported. Given the risks associated with complete heart block, an accurate delineation of the scope of this problem would be useful as a baseline for comparison of surgery to new interventional techniques and for informed consent of parents.

The aim of our retrospective study was to determine the incidence of early and delayed heart block in patients after surgical repair of the more common congenital heart lesions involving VSDs.

\section{METHODS}

Emory University and Children's Healthcare of Atlanta Institutional Review Board approval of retrospective medical record review was granted for this study. Patients were identified by screening the cardiac surgery database. All patients who underwent repair of VSD, atrioventricular (AV) canal, and tetralogy of Fallot at Children's Healthcare of Atlanta, Egleston Hospital, between January 1, 1999, and December 31, 2004, were considered for enrollment in the study. Patients with concomitant ligation of patent ductus arteriosus or closure of atrial septal defects were included. Those who required more complex procedures such as arch reconstructions or arterial switch procedures were excluded, as were those with heterotaxy syndrome or AV discordance.

The hospital records were reviewed and demographic and perioperative variables were abstracted, with particular attention paid to the postoperative conduction status. To identify cases of late complete heart block, we reviewed the hospital records, outpatient cardiology office notes, electrocardiogram reports, and the Sibley Heart Center pacemaker database. 


\section{Abbreviations and Acronyms}

$\mathrm{AV}=$ atrioventricular

VSD $=$ ventricular septal defect

\section{Statistical Analysis}

Data are presented as medians (ranges). Categorical variables were compared by $\chi^{2}$ analysis or Fisher's exact test as appropriate. Analysis of variance was used for continuous variables.

\section{RESULTS}

The study cohort included 922 patients (472 male) with the following diagnoses: AV canal, 197; tetralogy of Fallot, 222; and VSD, 503. At the time of surgery, the median age was 6 months (0-444 mo) and weight was $5.8 \mathrm{~kg}(1.3-116$ $\mathrm{kg})$. The median cardiopulmonary bypass time was 80 minutes (25-422 minutes), aortic crossclamp time was 45 minutes (0-238 minutes), and hospital length of stay was 4 days (1-244 days). The majority of the defects were closed with a Dacron patch using a running suture technique.

\section{Postoperative Heart Block}

Early postoperative heart block occurred in 21 (2.3\%) of 922 patients (Table 1). Of the 21 patients with early postoperative heart block, $13(1.4 \%)$ had temporary block with return of conduction a median of 3 days (1-14 days) after surgery. Three of these patients had second-degree AV block and the remaining 10 had complete (third-degree) block.

The remaining $8(0.9 \%)$ patients did not recover conduction and required placement of a permanent pacemaker a median of 9 days (6-20 days) after surgery. At last follow-up, 2 of these 8 patients have recovered conduction and no longer use their pacemakers. The distribution of postoperative transient AV block and pacemaker implantation by diagnosis is summarized in Table 1.

\section{Delayed Heart Block}

Of the 922 patients, 8 had permanent pacemakers placed in the immediate postoperative period and there were 9 perioperative deaths, leaving 905 patients at risk for delayed heart block. Three $(0.3 \%)$ patients subsequently had second- or third-degree AV block and had pacemakers placed at 2, 8, and 16 months after surgery. Details regarding these 3 patients are included in Table 2 .
TABLE 1. Postoperative AV block: transient and permanent pacemaker implanted

\begin{tabular}{lcccc}
\hline & $\begin{array}{c}\text { AV canal } \\
(\mathbf{n}=\mathbf{1 9 7})\end{array}$ & $\begin{array}{c}\text { TOF } \\
(\mathbf{n}=\mathbf{2 2 2})\end{array}$ & $\begin{array}{c}\text { VSD } \\
(\mathbf{n}=\mathbf{5 0 3})\end{array}$ & $\boldsymbol{P}$ value* \\
\hline Transient & $3(1.5 \%)$ & $4(1.8 \%)$ & $6(1.2 \%)$ & .8 \\
Pacemaker implanted & $2(1 \%)$ & $3(1.4 \%)$ & $3(0.6 \%)$ & .6 \\
\hline$A V$, Atrioventricular; $T O F$, tetralogy of Fallot; $V S D$, ventricular septal defect. * $\chi^{2}$ \\
$\begin{array}{l}\text { analysis of the incidence of transient or permanent } \\
\text { subgroup. }\end{array}$
\end{tabular}

There were 8 late deaths a median of 31 months (7-45 months) after surgery. None of those who died late had transient heart block in the postoperative period. The AV conduction status was documented as normal in 4 of these patients immediately before death, and 1 child was documented as being in normal sinus rhythm 2 months before her death of reported sepsis. It is unlikely that AV block was the cause of death in these 5 patients. However, the conduction status of the remaining 3 patients who died 20, 33, and 34 months after surgery is unknown. Including these 3 patients as possible cases of delayed AV block, the incidence would increase to $6(0.7 \%)$ of 905 patients.

Two of the 3 patients with documented delayed AV block had transient postoperative AV block. Including the 3 patients who died late with unknown conduction status, none of whom had transient block, there was a statistically significant association between transient postoperative AV block and delayed AV block; delayed block developed in $2(15 \%)$ of 13 with transient block versus $4(0.4 \%)$ of 892 without transient block $(P=.003)$. There were no statistically significant associations between the occurrence of delayed AV block and any other perioperative variable, including gender, age and weight at surgery, cardiac diagnosis, cardiopulmonary bypass time, aortic crossclamp time, or intensive care unit or hospital length of stay.

\section{DISCUSSION}

Whereas early AV block has been relatively widely studied in the past, the incidence of delayed heart block has not been clearly defined. Liberman and colleagues ${ }^{4}$ described 15 patients who initially went home in normal sinus rhythm after a surgical procedure and subsequently had a pacemaker placed $6.8 \pm 7.3$ years later. Unfortunately, the number of patients at risk for delayed AV block was not reported, so the incidence of this complication could not be calculated. However, it is interesting to note that $3(20 \%)$ of the 15

TABLE 2. Characteristics of patients with delayed AV block

\begin{tabular}{clcccc}
\hline Patient & Diagnosis & Age at surgery (mo) & Postoperative transient heart block & Interval to pacemaker (mo) & Rhythm before pacemaker \\
\hline 1 & CAVC & 2 & No & 2 & Third-degree block \\
2 & VSD & 4 & Yes & 8 & Second-degree block \\
3 & TOF & 6 & Yes & 16 & Second-degree block \\
\hline
\end{tabular}

$C A V C$, Complete atrioventricular canal; $V S D$, ventricular septal defect; $T O F$, tetralogy of Fallot. 
patients had transient postoperative heart block, which is comparable with our findings. In the current study, the occurrence of transient postoperative AV block was found to be significantly associated with delayed AV block.

Identification of the incidence of delayed AV block after surgical closure of VSDs is potentially important because it does not exist in the literature and it can provide a point of comparison for new techniques such as transcatheter or perventricular VSD device closure. The data in the literature regarding conduction-related complications of VSD devices suggest that this particular complication may be a serious concern. Butera and associates ${ }^{8}$ reported on 100 transcatheter device closures with a $2 \%$ incidence of permanent early block, a 3\% incidence of transient block (including 2 patients who recovered conduction only after removal of the device), and a $4 \%$ incidence of delayed block within 39 months of follow-up. In a more recent article, Predescu and colleagues ${ }^{9}$ reported a $20 \%$ incidence of delayed AV block after 20 device closures.

Although transcatheter and perventricular device closure of VSDs is clearly evolving and the devices will undoubtedly improve over time, it is incumbent on surgical programs to provide baseline data for evaluation of these new techniques. The incidence of delayed AV block for our cohort of patients including several cardiac diagnoses was $0.3 \%$ to $0.7 \%$ at a median follow-up of 4.1 years, which seems to be quite a bit lower than recently published device series. These data clearly indicate the need for continued follow-up of these patients regardless of the technique used.

\section{Limitations}

This is a retrospective chart review, which relied on available medical records. Incomplete reporting of the conduction status of 3 of the patients who died late after surgery limited our ability to more accurately determine the incidence of late complete heart block, resulting in a delayed AV block incidence of $0.3 \%$ to $0.6 \%$. Also, the mean follow-up time of 4 years provides only midterm data, which cannot be considered complete given the many reports of delayed AV block presenting much later than 4 years after surgery. ${ }^{4,70}$ Finally, patients could have moved out of our medical system after their most recent follow-up, which is another limitation of such a retrospective medical record review study.

\section{CONCLUSIONS}

The incidence of late complete heart block after surgical repair of uncomplicated congenital cardiac lesions involving a VSD is relatively low at $0.3 \%$ to $0.7 \%$. These data have been lacking in the literature and provide an important point of comparison for evaluation of new techniques for management of these patients. This information underscores the importance of long-term follow-up for these patients, particularly those children who have transient postoperative AV block.

\section{References}

1. Hoffman J. Incidence, mortality, and natural history. In: Anderson R, Baker E, Macartney F, Rigby ML, Shinebourne EA, Tynan M, eds. Paediatric cardiology. Edinburgh: Churchill Livingstone; 2005. p.111-40.

2. Andersen HØ, de Leval MR, Tsang VT, Elliott MJ, Anderson RH, Cook AC. Is complete heart block after surgical closure of ventricular septum defects still an issue? Ann Thorac Surg. 2006;82:948-57.

3. Kim MH, Deeb GM, Eagle KA, Bruckman D, Pelosi F, Oral H, et al. Complete atrioventricular block after valvular heart surgery and the timing of pacemaker implantation. Am J Cardiol. 2001;87:649-51.

4. Liberman L, Pass R, Hordof A, Spotnitz H. Late onset of heart block after open heart surgery for congenital heart disease. Pediatr Cardiol. 2007;29:56-9.

5. Wolff G, Rowland T, Ellison R. Surgically induced right bundle-branch block with left anterior hemiblock: an ominous sign in postoperative tetralogy of Fallot. Circulation. 1972;46:587-94.

6. Weindling SN, Saul JP, Gamble WJ, Mayer JE, Wessel D, Walsh EP. Duration of complete atrioventricular block after congenital heart disease surgery. Am J Cardiol. 1998;82:525-7.

7. Moss A, Klyman G, Emmanouilides G. Late onset complete heart block. Am J Cardiol. 1972;30:884-7.

8. Butera G, Carminati M, Chessa M, Piazza L, Micheletti A, Negura DG, et al. Transcatheter closure of perimembranous ventricular septal defects: early and long-term results. J Am Coll Cardiol. 2007;50:1189-95.

9. Predescu D, Chaturvedi RR, Friedberg MK, Benson LN, Ozawa A, Lee KJ. Complete heart block associated with device closure of perimembranous ventricular septal defects. J Thorac Cardiovasc Surg. 2008;136:1223-8.

10. Fukuda T, Nakamura Y, Iemura J, Oku H. Onset of complete atrioventricular block 15 years after ventricular septal defect surgery. Pediatr Cardiol. 2002;23: $80-3$. 